\title{
Ectopic Atrial Tachycardia
}

National Cancer Institute

\section{Source}

National Cancer Institute. Ectopic Atrial Tachycardia. NCI Thesaurus. Code C99113.

A disorder characterized by an electrocardiographic finding of atrial tachycardia that does not originate from the sinoatrial node. 